\title{
Spatial abundance and human biting rate of Anopheles arabiensis and Anopheles funestus in savannah and rice agro-ecosystems of Central Tanzania
}

\author{
Leonard E.G. Mboera, ${ }^{1}$ Veneranda M. Bwana, ${ }^{2}$ Susan F. Rumisha, ${ }^{1}$ Grades Stanley, ${ }^{1}$ \\ Patrick K. Tungu, ${ }^{2}$ Robert C. Malima ${ }^{2}$ \\ ${ }^{1}$ National Institute for Medical Research, Dar es Salaam; ${ }^{2}$ Amani Medical Research Centre, \\ Muheza, Tanzania
}

\author{
Correspondence: Leonard E.G. Mboera, National Institute for Medical \\ Research, 3 Barack Obama Drive, 9653 Dar es Salaam, Tanzania. \\ Tel: +255.754.314701 - Fax: +255.222.121360. \\ E-mail: Imboera@nimr.or.tz
}

Key words: Malaria; Anopheles arabiensis; Anopheles funestus; ecosystem; Tanzania.

Ethical considerations: this study received an ethical approval from the Medical Research Coordinating Committee of the National Institute for Medical Research, Tanzania. Permission to enter into houses was obtained from heads of the respective households after explaining the objective of the study.

Conflict of interest: the authors declare no potential conflict of interest.

Contributions: LEGM conceived the study, was the project coordinator and led the writing of this article. SFR led the study design, data analysis and interpretation. VMB, GS, RCK provided technical support during project implementation, and contributed to data collection. PT did mosquito genotyping. All authors contributed to the study design, interpretation, and drafting of the article. All authors read and approved the final version of the manuscript.

Acknowledgements: the authors would like to acknowledge Rose Mary Nguruwe, John Lindi, and Dionis Rwegoshora for their excellent field and technical assistance during data collection. Drs. Stephen M. Magesa and Eliningaya J. Kweka are thanked for their critical review of the earlier version of the manuscript. The National Institute for Medical Research and the Sokoine University of Agriculture are thanked for the logistical support. This manuscript is published with permission from Director General, National Institute for Medical Research, Tanzania.

Funding: the study received financial assistance from the International Development Research Centre of Canada through Integrated Research Partnership for Malaria Control through an Ecohealth Approach in Africa (IDRC Project No. 104263-004).

Received for publication: 26 January 2015.

Revision received: 16 February 2015.

Accepted for publication: 24 February 2015.

(C) Copyright L.E.G. Mboera et al., 2015

Licensee PAGEPress, Italy

Geospatial Health 2015; 10:322

doi:10.4081/gh.2015.322

This article is distributed under the terms of the Creative Commons Attribution Noncommercial License (by-nc 3.0) which permits any noncommercial use, distribution, and reproduction in any medium, provided the original author(s) and source are credited.

\begin{abstract}
This study was carried out to determine the spatial variations in malaria mosquito abundance and human biting rate in five villages representing rice-irrigation and savannah ecosystems in Kilosa District, central Tanzania. The study involved five villages namely Tindiga and Malui (wetland/rice irrigation), Twatwatwa and Mbwade (dry savannah) and Kimamba (wet savannah). Indoor mosquitoes were sampled using Centers for Disease Control and Prevention light traps in three houses in each village. Anopheles gambiae s.l. molecular identification was carried out using polymerase chain reaction (PCR). A total of 936 female mosquitoes were collected. About half (46.9\%) were malaria mosquitoes (Anopheles gambiae s.l. $=28.6 \%$; An. funestus $=18.3 \%)$. A total of $161(60.1 \%)$ of the morphologically identified An. gambiae s.l. (268) and subjected to PCR analysis for speciation were genotyped as An. arabiensis. The An. funestus complex mosquitoes were composed of An. funestus funestus and An. rivulorum at the 5:1 ratio. On average, 17.9 Anopheles mosquitoes were collected per village per day. Two-thirds $(62.8 \%)$ of the malaria mosquitoes were collected in Malui (rice agro-ecosystem) and the lowest number (2.3\%) in Twatwatwa (dry savannah ecosystem). The biting rate per person per night for An. arabiensis+An. funestus s.s. was highest in Malui (46.0) and lowest in Twatwatwa (1.67). The parity rate of the $A n$. funestus mosquitoes was lower compared to that of An. arabiensis and none of the mosquitoes was infected with malaria sporozoites. In conclusion, An. arabiensis is the most abundant malaria vector in Kilosa district and its variation is related to the ecological system. The heterogeneity in malaria mosquito abundance and human biting rate could be used to guide selection of locally appropriated control interventions.
\end{abstract}

\section{Introduction}

In Tanzania malaria is mainly transmitted by Anopheles gambiae, An. arabiensis and An. funestus (White, 1974). Other important vectors include An. merus (Mnzava, 1991; Kigadye, 2006), An. rivulorum and An. marshallii (Wilkes et al., 1996; Malima, 1999; Magesa et al., 1991). Malaria transmission in most areas of Tanzania has been generalized by zone, region or district (Clyde, 1967). However, it has been observed in Sub-Saharan Africa that there are variations in anopheline mosquito composition and malaria transmission locally, i.e. within districts (even within villages) and between seasons (Ijumba et al., 2002; 
Appawu et al., 2004; Mboera et al., 1997, 2007, 2010). Craig et al. (1999) and Hay et al. (2000) have demonstrated the existence of important, small-scale, local variations in the malaria transmission and endemicity across Africa as a whole. Differences in micro-ecological and socioeconomic factors, including vector density heterogeneity, mosquito survival, vector host contact and their innate feeding preference are likely to have contributed to these variations (Smith et al., 1995).

Malaria mosquito abundance varies in space and time, hence displaying species-specific seasonality. Generally, malaria transmission in Tanzania has been described to be higher in rice irrigation ecosystems than in any other ecosystem (Ijumba and Lindsay, 2001; Ijumba et al., 2002; Mboera et al., 2010). It has already been observed that irrigated cultivation enhances population development of many malaria mosquito species and is associated with high malaria transmission in subSaharan Africa (Dossou-Yovo et al., 1994). Generally, the biting rate is highest shortly after the mosquito density peak, near breeding sites where adult mosquitoes emerge and around the edges of areas where humans are aggregated (Smith et al., 2005). These sources of spatial and temporal heterogeneity in the distribution of mosquito populations are associated with biting rate variability, the proportion of mosquitoes that are infectious and that for human infection (Smith et al., 2005). Similar to mosquito density, the annual entomological inoculation rates (EIR) estimates in Tanzania display marked temporal and spatial variation, with the likelihood of communities in irrigation ecosystems experiencing higher EIR throughout the year (Mboera et al., 2010).

The variation in mosquito abundance and EIR between ecosystems and land use may be explained by differences in the ecological settings, and more specifically by the availability of favorable breeding sites (Dossou-Yovo et al., 1994; Appawu et al., 2004; Mboera et al., 2010). Malaria transmission is influenced by variations in ecological conditions, which have impact on the biology of the parasite and its mosquito vector. On the other hand, malaria transmission influences daily life and socio-economic conditions, which impact human vulnerability and vector habitats. These variables can lead to conditions and environments conducive to mosquito proliferation, human exposure to biting mosquitoes translating into enhanced malaria transmission (Mboera et al., 2011; Lowe et al., 2013).

Only a few studies in Tanzania have investigated the variations in malaria mosquito density and EIR in relation to agro-ecosystems or land use (Ijumba and Lindsay, 2001; Ijumba et al., 2002; Mboera et al., 2011). In northern Tanzania, Ijumba and Lindsay (2001) observed that the potential risk of malaria due to An. arabiensis and An. funestus was four-fold higher in rice agro-ecosystem than in sugarcane or savannah ecosystems. In East-Central Tanzania, Mboera et al. (2011) reported that the mean annual inoculation rate for An. gambiae s.l. was significantly higher in traditional flooding irrigation than in other agroecosystems. However, there is limited knowledge of the malaria vector species and transmission indices in different ecosystems in central Tanzania.

This study was carried out to determine the spatial variations in mosquito abundance and biting rates in five villages representing different ecosystems and daily activities in this area.

\section{Materials and Methods}

\section{Study area}

The study was carried out in Kilosa District ( $5^{\circ} 55^{\prime}-7^{\circ} 53^{\prime} \mathrm{S} ; 36^{\circ} 30^{\prime}$ $37^{\circ} 30 \mathrm{E}$ ) in central Tanzania. The district has a total surface area of about $14,400 \mathrm{~km}^{2}$, a population of 489,513 people (NBS, 2013) and a tropical climate, characterized by a monomodal rainfall pattern begining in October with a peak in April-May. The mean annual temperature is $25^{\circ} \mathrm{C}$. Agriculture is the main activity and most people are smallholders or work at estate farms. The main crops are maize, rice, sorghum, beans, cassava, sweet potatoes, cotton, sunflower, sesame and sisal. Free-range livestock production is an important type of land use in the district.

The study was conducted in five villages, namely Tindiga and Malui (rice irrigation ecosystem), Twatwatwa, Mbwade (dry savannah ecosystem) and Kimamba (wet savannah ecosystem). The area has been described recently by Rumisha et al. (2014). Tindiga and Malui are in the south-eastern part of the district and are characterized by swampy flatland and wetlands belonging to the Kilangali alluvial basin. Most of the communities in Tindiga and Malui are small-scale rice farmers using traditional ground flooding irrigation practice. Mbwade and Twatwatwa are located in the North-Eastern part of the district and are characterized by dry savannah type of vegetation, with most of the areas covered by short grasses, trees and shrubs that provide a wide range of pasture for livestock grazing (Figure 1). The villages are mainly inhabited by Maasai pastoralists keeping cattle, sheep, goats and donkeys. Kimamba, a fast growing township with mixed livelihood routines, which include maize farming and large sisal-producing estates. There are also many sisal factories and grain mills that attract employment.

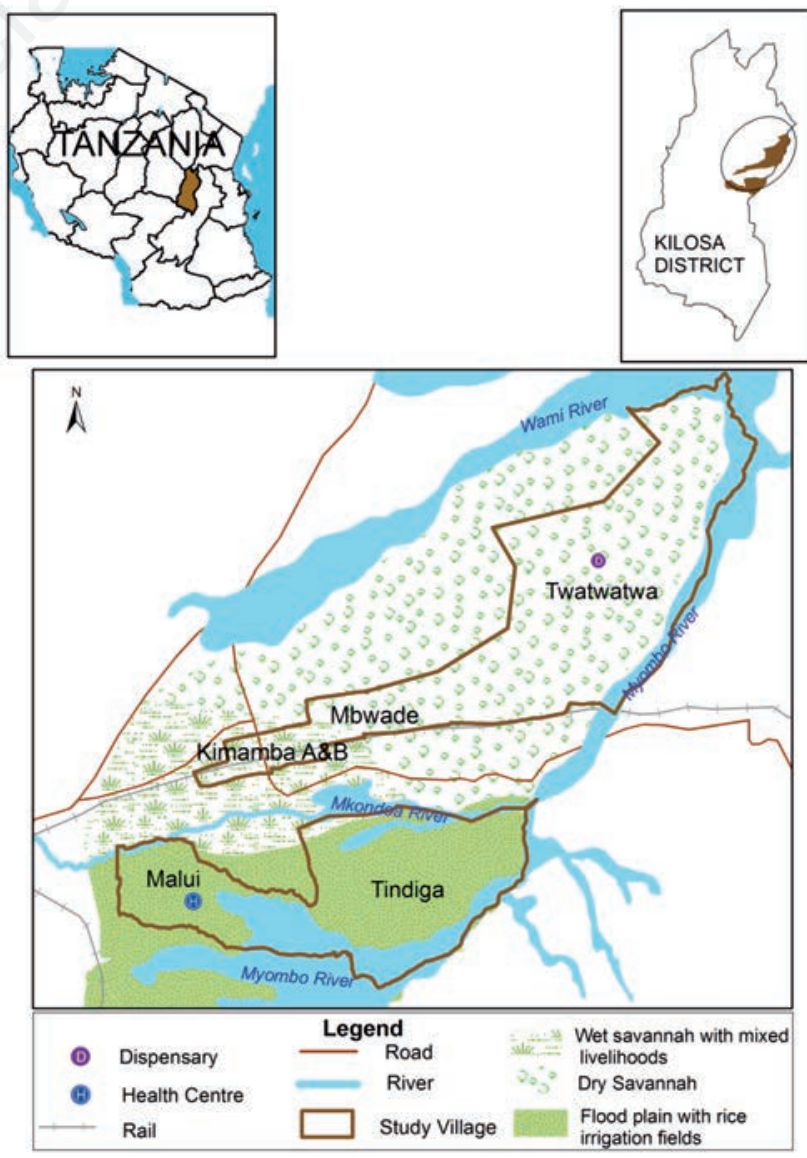

Figure 1. Map of the study area in Kilosa District in Tanzania. 


\section{Mosquito collection, identification and processing}

Adult mosquitoes were sampled in three houses in each of the five villages for three consecutive days in May 2012. Mosquito collections were done using Centers for Disease Control and Prevention (CDC) light traps (J.W. Hock Ltd, Gainesville, FL, USA). Each light trap was hung at the top of the foot-end of the bed with an adult person sleeping under a untreated mosquito net (Mboera et al., 1998). The light traps were set at $18.00 \mathrm{~h}$ and collected the following morning at $06.00 \mathrm{~h}$.

Collected mosquitoes were kept in cool boxes and brought to a field laboratory for identification and further processing. At the field laboratory, mosquitoes were anaesthetised, sorted, counted and identified morphologically with respect to species (Gillies and De Meillon, 1968; Gillies and Coetzee, 1987). Parity of female An. funestus and An. gambiae s.l. from a sample of unfed mosquitoes was determined using the conventionally used technique described by Detinova (1962). The presence of malaria sporozoites in the salivary glands was determined by examining the salivary glands under microscope. A proportion of each catch of An. gambiae s.l. and An. funestus s.l. was kept dry on silica gel in $0.5 \mathrm{~mL}$ polypropylene tubes for later genotyping using the polymerase chain reaction (PCR) technique. Briefly, genomic DNA was extracted from the whole female mosquito using standard methods. The PCR amplification for An. gambiae s.l. and An. funestus sibling species molecular identification was carried out using their respective specific diagnostic primers according to the standard PCR method (Scott et al., 1993).

\section{Data analysis}

Data were entered in Epi Info database version 6 (CDC, Atlanta, GA, USA) and then transferred to STATA statistical analysis software package version 11 (Stata Statistical Software, College Station, TX, USA). The parity rates were determined as the proportion of Anopheles mosquitoes found to be parous. The biting rates were calculated as the number of Anopheles biting per person per night using the formula by Lines et al. (1991). Maps were created using ArcGIS version 9.3 (ESRI, Redlands, CA, USA).

\section{Results}

A total of 936 female mosquitoes were collected in 15 houses. Some $46.9 \%$ were malaria mosquitoes (An. gambiae $=28.6 \%$; An. funestus $=18.3 \%$ ). Culex quinquefasciatus accounted for $30.3 \%$ of the total mosquito population. Other mosquito species accounted for $22.8 \%$. The largest proportion of the malaria mosquitoes (62.8\%) was collected in Malui and the smallest (2.3\%) in Twatwatwa (Table 1). An. funestus mosquitoes were collected in all villages except in Twatwatwa. Malui accounted for the largest proportion (69.6\%) of the An. funestus collections. On average, 17.9 Anopheles mosquitoes were collected per village per day (Kimamba $=3 ;$ Malui=26; Tindiga $=6 ;$ Mbwade $=3$; Twatwatwa=1). A total of $161(60.1 \%)$ of the morphologically identified An. gambiae s.l. (268) were further subjected to PCR analysis for speciation and all of them were genotyped as An. arabiensis. Eighty-one An. funestus complex mosquitoes were also subjected to PCR analysis. The An. funestus funestus to An. rivulorum ratio was 5:1 (Table 2).

The biting rate for An. gambiae s.l. (26.8) was higher than that for An. funestus (17.1). On average an individual human received 43.9 Anopheles bites per night. The biting rate per person per night for the two malaria mosquitoes was highest in Malui (46.0) and lowest in Twatwatwa (1.7) (Figure 2).

The overall parity rates for An. arabiensis and An. funestus were 72.1 and $42.6 \%$, respectively (Table 3). A total of 62 and 54 An. arabiensis and An. funestus, respectively, were examined for presence of malaria sporozoites by salivary gland microscopy. None of the mosquitoes was infected.

Table 1. Number and percentage of mosquito species collected by village and ecosystem.

\begin{tabular}{|c|c|c|c|c|c|c|c|}
\hline Ecosystem & Village & $\begin{array}{l}\text { Anopheles } \\
\text { gambiae s.l. }\end{array}$ & $\begin{array}{l}\text { Anopheles } \\
\text { funestus }\end{array}$ & $\begin{array}{l}\text { Culex quinque } \\
\text { fasciatus }\end{array}$ & Other species & $\begin{array}{c}\text { No. of malaria } \\
\text { mosquitoes }\end{array}$ & Total \\
\hline Wet savannah & Kimamba & 18 & 2 & 99 & 2 & $20(4.6)$ & $121(12.9)$ \\
\hline Rice irrigation & Malui & 157 & 119 & 16 & 162 & $276(62.9)$ & $454(48.5)$ \\
\hline Rice irrigation & Tindiga & 58 & 43 & 24 & 43 & $101(23)$ & $168(17.9)$ \\
\hline Dry savannah & Mbwade & 25 & 7 & 7 & 6 & $32(7.3)$ & $45(4.8)$ \\
\hline Dry savannah & Twatwatwa & 10 & 0 & 138 & 0 & $10(2.3)$ & $148(15.8)$ \\
\hline Total (n) & 268 & 171 & 284 & 213 & 439 & 936 & \\
\hline Total (\%) & 28.6 & 18.3 & 30.3 & 22.8 & 46.9 & 100.0 & \\
\hline
\end{tabular}

Values within brackets are represented as percentage.

Table 2. Malaria mosquito speciation by polymerase chain reaction by village.

\begin{tabular}{|c|c|c|c|c|c|c|}
\hline Species & Kimamba & Malui & Mbwade & Tindiga & Twatwatwa & Total \\
\hline Anopheles arabiensis & 17 & 95 & 10 & 32 & 7 & $161(60.98)$ \\
\hline An. funestus funestus & 0 & 59 & 1 & 21 & 0 & $81(30.68)$ \\
\hline Anopheles rivulorum & 1 & 4 & 2 & 9 & 0 & $16(6.06)$ \\
\hline Not amplified/faint & 0 & 4 & 0 & 2 & 0 & $6(2.28)$ \\
\hline Total & 18 & 162 & 13 & 64 & 7 & 264 \\
\hline
\end{tabular}

Values within brackets are represented as percentage. 


\section{Discussion}

Both the abundance and house density of the Anopheles mosquitoes collected from the two rice-farming villages were higher than anywhere else. The variation in the abundance of Anopheles mosquitoes was observed between villages and between different ecosystems. Malaria mosquito abundance and biting rates vary markedly in space and time. Spatially, the variables can vary over the space of a few kilometres (Kulkarni et al., 2010; Mboera et al., 2010). This spatial heterogeneity in abundance and biting indicates variation in environmental conditions that affect mosquito distribution (Ernst et al., 2006; Kulkarni et al., 2010).

All samples of An. gambiae s.l. were genotyped as An. arabiensis, in accordance with previously reported geographical distribution of $A n$. gambiae sibling species across Tanzania (White, 1974; Mnzava and Kilama, 1986). On the other hand, the ongoing climatic changes across Africa favors the environmental variables, which very much support the increased distribution of An. arabiensis, which in turn exhibits greater ecological flexibility than other members of the An. gambiae complex from a historical perspective (Meyrowitsch et al., 2011). An. arabiensis and An. funestus were the major malaria vectors sampled in our study. Anopheles rivulorum has been reported as a vector of malaria in NorthEastern Tanzania (Magesa et al., 1991; Wilkes et al., 1996; Malima, 1999) and is known to be the next most widespread species in the $A n$. funestus group in Africa. Despite its known role in malaria transmission, its impact as a malaria vector has not been fully studied (Awolola et al., 2003, 2005; Temu et al., 2007; Kweka et al., 2008). Previous studies in North-Eastern Tanzania by Gillies and Smith (1960) reported that An. rivulorum has the potential to replace An. funestus s.s. after indoor residual spraying eliminates the more abundant malaria mosquito species. The sympatric occurrence of An. funestus s.s. and An. rivulorum as observed in our study has also been reported in coastal Tanzania (Temu et al., 2007). To our knowledge, this is the first time An. rivulorum is reported from Central Tanzania. On average, an individual human received about 44 bites of malaria mosquitoes each night. The biting rate per person per night for the two malaria mosquitoes was higher among the communities in the rice irrigation ecosystem than in those in the savannah ecosystem. The differences in vector composition between the ecosystems are likely to have impact on the level of malaria transmission in the areas studied. A recent investigation in the same study villages indicates that despite the low number and absence of sporozoite-infected Anopheles mosquitoes, malaria infection is prevalent. Malui and Tindinga, which had the largest proportions of malaria mosquitoes, also had the highest prevalence of malaria infection (Mboera et al., 2013a, 2013b). Previous studies indicated a higher endemicity of malaria in the district (Eriksen et al.,
2004; Makundi et al., 2006; Uddenfeldt Wort et al., 2006).

Despite having high parity rates estimated at over $60 \%$, none of the mosquitoes was found to carry sporozoites. The absence of infected mosquitoes is likely to be attributed to the low number of mosquitoes collected and the method used to examine them for sporozoites. The relatively low mosquito densities and absence of sporozoites in the current study is likely to be a result of a high use of mosquito nets in the district. Over $83 \%$ of the households had insecticide-treated mosquito nets during the time of the survey (Shayo et al., 2015). A more intensive longitudinal study is recommended to establish malaria transmission intensity in the area.

\section{Conclusions}

An. arabiensis is the most abundant malaria vector in the Kilosa district and its variation is related to the ecological system. The mosquito is more abundant in rice irrigation than in savannah ecosystems. The heterogeneity in malaria mosquito abundance and human biting rate observed in this study could be used to guide selection of locally appropriated control interventions. It is therefore important that this variation is considered when designing appropriate malaria intervention and rice farming systems.

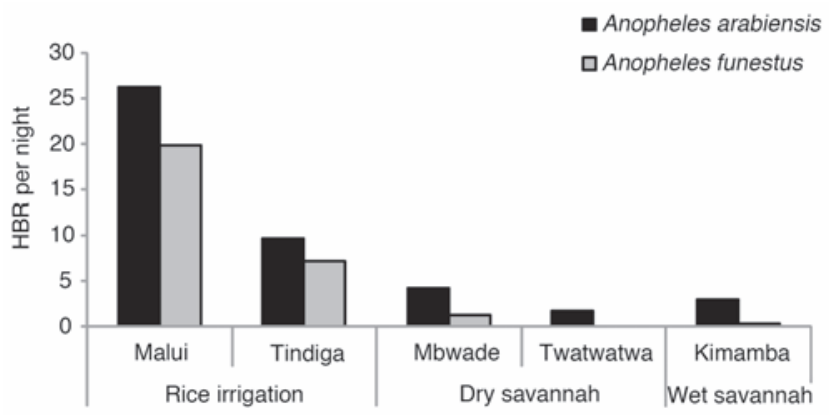

Figure 2. Malaria mosquito biting rate per person per night.

Table 3. Parity rates of Anopheles arabiensis and Anopheles funestus by village in Kilosa.

\begin{tabular}{lcccc} 
Village & \multicolumn{2}{c}{$\begin{array}{c}\text { Anopheles arabiensis } \\
\text { Total dissected }\end{array}$} & $\begin{array}{c}\text { Anopheles funestus } \\
\text { Parity }\end{array}$ & Total dissected \\
Kimamba & 1 & 0.0 & 2 & 100 \\
Malui & 50 & 76.0 & 24 & 58.3 \\
\hline Mbwade & 14 & 71.4 & 5 & 80.0 \\
Tindiga & 16 & 62.5 & 19 & 68.4 \\
\hline Twatwatwa & 5 & 80.0 & 4 & 75.00 \\
Total & 86 & 72.1 & 54 & 42.6 \\
\hline
\end{tabular}

${ }^{\circ}$ Parity, number parous/total number dissected $\times 100$. 


\section{References}

Appawu M, Owusu-Agyei S, Dadzie S, Asoala V, Anto F, Koram K, Rogers W, Nkrumah F, Hoffman SL, Fryauff DJ, 2004. Malaria transmission dynamics at a site in northern Ghana proposed for testing malaria vaccines. Trop Med Int Health 9:164-70.

Awolola TS, Ibrahim K, Okorie T, Koekemoer LL, Hunt RH, Coetzee M, 2003. Species composition and biting activities of anthropophilic Anopheles mosquitoes and their role in malaria transmission in a holoendemic area of southern Nigeria. Afr Entomol 11:227-32.

Awolola TS, Oyewole I0, Koekemoer LL, Coetzee M, 2005. Identification of three members of the Anopheles funestus (Diptera: Culicidae) group and their role in malaria transmission in two ecological zones in Nigeria. T Roy Soc Trop Med H 99:525-31.

Clyde CF, 1967. Malaria in Tanzania. Oxford University Press, London, UK.

Craig MH, Snow RW, Le Sueur D, 1999. A climate-based distribution model of malaria transmission in sub-Saharan Africa. Parasitol Today 15:105-11.

Detinova T, 1962. Age-grouping methods in diptera of medical importance with special reference to some vectors of malaria. World Health Organization, Geneva, Switzerland.

Dossou-Yovo J, Doannio J, Riviere F, Duval J, 1994. Rice cultivation and malaria transmission in Bouake City (Cote d'Ivore). Acta Trop 57:914.

Eriksen J, Mwankusye S, Mduma S, Kitua A, Swedberg G, Tomson G, Gustafsson LL, Warsame M, 2004. Patterns of resistance and DHFR/DHPS genotypes of Plasmodium falciparum in rural Tanzania prior to the adoption of sulfadoxine-pyrimethamine as first-line treatment. T Roy Soc Trop Med H 98:347-53.

Ernst K, Adoka S, Kowuor D, Wilson M, John C, 2006. Malaria hotspot areas in a highland Kenya site are consistent in epidemic and nonepidemic years and are associated with ecological factors. Malaria J 5:78.

Gillies MT, Coetzee M, 1987. A supplement to the Anophelinae of Africa South of the Sahara (Afrotropical region). South African Institute for Medical Research Publ., Johannesburg, South Africa.

Gillies MT, De Meillon B, 1968. The Anophelinae of Africa South of the Sahara. South African Institute for Medical Research Publ., Johannesburg, South Africa.

Gillies MT, Smith A, 1960. The effect of a residual house spraying campaign in East Africa on species balance in the Anopheles funestus group: the replacement of Anopheles funestus Giles by Anopheles rivulorum Leeson. B Entomol Res 51:243-52.

Hay SI, Rogers DJ, Toomer JF, Snow RW, 2000. Annual Plasmodium falciparum inoculation rates (EIR) across Africa: literature survey, Internet access and review. T Roy Soc Trop Med H 94:113-7.

Ijumba J, Lindsay S, 2001. Impact of irrigation on malaria in Africa: paddies paradox. Med Vet Entomol 15:1-11.

Ijumba J, Mosha F, Lindsay S, 2002. Malaria transmission risk variations derived from different agricultural practices in an irrigated area of northern Tanzania. Med Vet Entomol 16:28-38.

Kigadye E, 2006. Mosquito abundance and malaria transmission in the Rufiji River Basin, Tanzania. PhD Thesis. University of Dar es Salaam, Tanzania.

Kulkarni M, Desrochers RE, Kerr JT, 2010. High resolution niche models of malaria vectors in northern Tanzania: a new capacity to predict malaria risk? PLoS One 5:e9396.

Kweka EJ, Mahande AM, Nkya WM, Assenga C, Lyatuu EE, Nyale E,
Mosha FW, Mwakalinga SB, Temu EA, 2008. Vector species composition and malaria infectivity rates in Mkuzi, Muheza District, north-eastern Tanzania. Tanzan J Health Res 10:46-9.

Lines JD, Curtis CF, Wilkes TJ, Njunwa KJ, 1991. Monitoring human biting mosquitoes in Tanzania with light-traps hung beside mosquito nets. B Entomol Res 81:77-84.

Lowe R, Chirombo J, Tompkins AM, 2013. Relative importance of climatic, geographic and socio-economic determinants of malaria in Malawi. Malaria J 12:416.

Magesa SM, Wilkes TJ, Mnzava AE, Njunwa KJ, Myamba J, Kivuyo, MD, Hill N, Lines JD, Curtis CF, 1991. Trial of pyrethroid impregnated bednets in an area of Tanzania holoendemic for malaria. Part 2. Effects on the malaria vector population. Acta Trop 49:97-108.

Makundi EA, Malebo HM, Mhane P, Kitua AY, Warsame, M, 2006. Role of traditional healers in the management of severe malaria among children below five years of age: the case of Kilosa and Handeni Districts, Tanzania. Malaria J 5:58.

Malima RC, 1999. Sporozoite rates and species identity of mosquitoes collected from highland and lowland in Tanzania. MSc Thesis. University of London, UK.

Mboera LEG, Kihonda J, Braks MA, Knols BJG 1998. Influence of centers for disease control light trap position, relative to a human-baited bed net, on catches of Anopheles gambiae and Culex quinquefasciatus in Tanzania. Am J Trop Med Hyg 59:595-6.

Mboera LEG, Mazigo HD, Rumisha SF, Randall K, 2013a. Towards malaria elimination and its implication for vector control, disease management and livelihoods in Tanzania. Malar Wld J 4:19.

Mboera LEG, Mlozi MRS, Rumisha SF, Bwana VM, Malima RC, Shayo EH, Mayala BK, Mlacha T, Nguruwe R, 2013b. Malaria, ecosystems and livelihoods in Kilosa district, Central Tanzania. National Institute for Medical Research, Dar es Salaam, Tanzania.

Mboera LEG, Mlozi MRS, Senkoro KP, Rwegoshora RT, Rumisha, SF, Mayala BK, Shayo EH, Senkondo E, Mutayoba B, Mwingira V, Maerere A, 2007. Malaria and agriculture in Tanzania: impact of land-use and agricultural practices on malaria burden in Mvomero district. National Institute for Medical Research, Dar es Salaam, Tanzania.

Mboera LEG, Pedersen EM, Salum FM, Msuya FH, Sambu EZ, 1997. Transmission of malaria and bancroftian filariasis in Magoda area, north-east Tanzania. Mal Infect Dis Africa 7:61-7.

Mboera LEG, Rwegoshora RT, Senkoro KP, Rumisha SF, Mayala BK, Mlozi MRS, Shayo EH, Senkondo E, Maerere A, 2010. Spatio-temporal variation in malaria transmission intensity in five agro-ecosystems in Mvomero District, Tanzania. Geosp Health 4:167-78.

Mboera LEG, Senkoro KP, Rumisha SF, Mayala BK, Shayo EH, Mlozi MR, 2011. Plasmodium falciparum and helminth coinfections among schoolchildren in relation to agro-ecosystems in Mvomero District, Tanzania. Acta Trop 112:95-102.

Meyrowitsch DW, Pedersen EM, Alifrangis M, Scheike TH, Malecela MN, Magesa M, Derua YA, Rwegoshora RT, Michael E, Simonsen $\mathrm{PE}, 2011$. Is the current decline in malaria burden in sub-Saharan Africa due to a decrease in vector population? Malaria J 10:188.

Mnzava AEP, Kilama WL, 1986. Observations on the distribution of species of the Anopheles gambiae in Tanzania. Acta Trop 43:27788.

Mnzava AP, 1991. Epidemiology and control of malaria transmission by residual house spraying with DDT and lambdacyhalothrin in two populations of the Anopheles gambiae complex in Tanga region, Tanzania. PhD Thesis. University of Basel, Switzerland.

NBS, 2013. 2012 population and housing census. Population distribution by age and sex: Tanzania. National Bureau of Statistics, Dar es 


\section{Article}

Salaam, Tanzania.

Rumisha SF, Zinga MM, Fahey CA, Wei D, Bwana VM, Mlozi MRS, Shayo EH, Malima RC, Mayala BK, Stanley G, Mlacha T, Mboera LEG, 2014. Accessibility, availability and utilisation of malaria interventions among women of reproductive age in Kilosa District in central Tanzania. BMC Health Serv Res 14:452.

Scott JA, Brogdon WG, Collins FH, 1993. Identification of single specimens of the Anopheles gambiae complex by the polymerase chain reaction. Am J Trop Med Hyg 49:520-9.

Shayo EH, Rumisha SF, Mlozi MRS, Bwana V, Mayala BK, Malima RC, Mlacha T, Mboera LEG, 2015. Social determinants of malaria and health care seeking patterns among rice farming and pastoral communities in Kilosa District of Central Tanzania. Acta Trop 141:41-9.

Smith DL, Dushoff J, Snow RW, Hay SI, 2005. The entomological inoculation rate and Plasmodium falciparum infection in African chil- dren. Nature 438:492-8.

Smith T, Charlwood JD, Takken W, Tanner M, Spiegelhalter DJ, 1995. Mapping the densities of malaria vectors within a single village. Acta Trop 59:1-18.

Temu EA, Minjas JN, Tuno N, Kawada H, Takagi M, 2007. Identification of four members of the Anopheles funestus (Diptera: Culicidae) group and their role in Plasmodium falciparum transmission in Bagamoyo coastal Tanzania. Acta Trop 102:119-25.

Uddenfeldt Wort U, Warsame M, Brabin BJ, 2006. Birth outcomes in adolescent pregnancy in an area with intense malaria transmission in Tanzania. Acta Obstet Gyn Scan 85:949-54.

White GB, 1974. The Anopheles gambiae complex and malaria transmission in Africa. T Roy Soc Trop Med H 68:278-301.

Wilkes TJ, Matola YG, Charlwood JD, 1996. Anopheles rivulorum, a vector of human malaria in Africa. Med Vet Entomol 10:108-10. 